\title{
KOREKSI GAYA GRAVITASI DAN EFEK GRAVITOELEKTROMAGNETISME BERDASARKAN ENTROPI GRAVITASI KUANTUM
}

\author{
Yuant Tiandho \\ Jurusan Fisika, Universitas Bangka Belitung \\ Jl. Kampus Peradaban, Balunijuk, Kep. Bangka Belitung, Indonesia \\ e-mail: yuant@ubb.ac.id
}

\begin{abstract}
In the weak-field limit condition, the gravitational force has a form that is analogous to the electromagnetic force. So that by using the analogy, we may propose a formula called gravitoelectromagnetism effect. Like the electromagnetic field, the gravity also predicted to has gravitoelectric field and gravitomagnetic field. This paper derive the expression of gravitational force as the entropic force according to correction of the generalized uncertainty principle (GUP) in the study of quantum gravity. Newton's gravitational force arise naturally due to the change of information (entropy) of a holographic screen that produced by object with mass $M$ and it can be detected by other object which has mass $m$. From the formulation of gravity it appears that in the surrounding of object with mass $M$ can be found the additional mass density which is indicated as a quantum foam. Therefore it needs to calculate the gravitoelectric field and the gravitomagnetic field of the rotating object and it was found that the result also influenced by the quantum fluctuations.
\end{abstract}

Keywords: gravitoelectromagnetism, gravity, quantum gravity, weak field

\begin{abstract}
ABSTRAK
Pada kondisi medan lemah gaya gravitasi memiliki bentuk yang analogi dengan gaya elektromagnetik, sehingga melalui analogi tersebut dapat diajukan suatu rumusan yang disebut dengan efek gravitoelektromagnetisme. Layaknya medan elektromagnetik, gravitasi juga diprediksi memiliki medan gravitoelektrik dan medan gravitomagnetik. Artikel ini mencoba menurunkan ungkapan gaya gravitasi sebagai gaya entropik berdasarkan koreksi dari generalized uncertainty principle (GUP) sesuai kajian gravitasi kuantum. Gaya gravitasi Newton muncul secara alami karena adanya perubahan informasi (entropi) dari layar holografik yang dihasilkan oleh objek bermassa $M$ dan terdeteksi oleh objek lain yang bermassa $m$. Dari rumusan gaya gravitasi yang diperoleh tampak bahwa di sekitar objek bermassa $M$ terdapat densitas massa tambahan yang dapat dipandang sebagai quantum foam. Dengan adanya indikasi tersebut artikel ini menghitung medan gravitoelektrik dan gravitomagnetik pada objek yang berotasi dan ternyata kedua medan yang dihasilkan juga dipengaruhi oleh adanya fluktuasi kuantum.
\end{abstract}

Kata kunci: gravitoelektromagnetisme, gravitasi, kuantum gravitasi, medan lemah 
Gravitasi merupakan interaksi yang telah sangat lama dipelajari oleh para fisikawan. Bahkan salah satu paradigma adalah memandang gravitasi sebagai bagian dari gaya fundamental penyusun alam semesta: elektromagnetik, nuklir kuat, nuklir lemah, dan gravitasi (Ciufolini, et al., 2013). Meskipun telah banyak teori diajukan untuk menjelaskan bagaimana gravitasi dapat bekerja, tetapi gravitasi hingga hari ini masih menyisakan sejumlah pertanyaan dan permasalahan yang belum juga dapat diselesaikan, diantaranya adalah masalah unifikasi dan hirarki (Paulson, et al., 2015). Dengan menggunakan mekanika kuantum (model standar) ketiga gaya, kecuali gravitasi, telah dapat digabungkan dalam satu cara pandang. Tetapi ketika teori gravitasi paling akurat, yaitu teori relativitas umum Einstein dikaji melalui mekanika kuantum (perturbatif) akan diperoleh kondisi divergensi yang tidak dapat direnormalisasi sehingga dibutuhkan suatu teori kuantum yang lengkap dari relativitas Einstein. Munculnya teori ini diharapkan dapat menjawab berbagai pertanyaan terkait awal mula alam semesta dan paradoks informasi lubang hitam (Maldacena, 2014).

Banyak fisikawan percaya bahwa gravitasi dan geometri ruang-waktu saling terhubung. Salah satu teori yang dikembangkan berdasarkan konsep tersebut adalah prinsip holografik. Bukti terkuat prinsip holografik terdapat pada kajian fisika lubang hitam, khususnya untuk menjelaskan mengapa entropi yang berkaitan dengan informasi dari lubang hitam bergantung atau tersimpan pada luasan horizon bukan pada volumenya (Papadodimas \& Raju, 2014). Dengan menggunakan prinsip holografik, Verlinde telah berhasil menurunkan hukum gravitasi Newton yang dinyatakan sebagai gaya entropik akibat perubahan jumlah informasi yang diasosiasikan dengan posisi suatu benda terhadap benda lainnya (Verlinde, 2011). Menurut Verlinde gravitasi Newton muncul secara alami akibat hubungan antara energi, entropi yang berkaitan dengan luas layar holografik, dan ungkapan temperatur berdasarkan prinsip ekuipartisi. Ide ini menarik karena ia diturunkan dari prinsip holografik yang memberikan harapan renormalisasi melalui prinsip korespondesi Anti de Sitter/Conformal field theory (AdS/CFT).

Pada penyusunan teori gravitasi kuantum, seperti pada teori string dan loop quantum gravity (LQG) yang menjadi cikal bakal prinsip holografik, dikenal adanya panjang minimum suatu objek yang berkaitan dengan panjang Planck. Sebagai contoh adalah string yang merupakan kemungkinan terkecil dalam analisis ruang-waktu dan tidak ada daerah ruang-waktu yang lebih kecil lagi (Dzierzak, et al., 2010; Amati, Ciafaloni \& Veneziano, 1989). Adanya panjang minimum tersebut memaksa kita untuk modifikasi teori ketidakpastian Heisenberg yang kemudian disebut dengan generalized uncertainty principle (GUP) sebagai (Garay, 1995):

$$
\delta x \delta p \geq \hbar+\frac{\alpha l_{p}^{2}}{\hbar} \delta p^{2}
$$

dengan $\delta x$ dan $\delta p$ masing-masing adalah ketidakpastian posisi dan momentum dari partikel kuantum, $l_{p}=\sqrt{\hbar G / c^{3}}$ adalah panjang Planck, dan $\alpha$ adalah suatu konstanta tak berdimensi yang nilainya bergantung pada model yang digunakan. Modifikasi teori ketidakpastian ini menyebabkan adanya koreksi entropi-gravitasi. Tentu saja, koreksi entropi ini akan membuat gaya gravitasi entropik yang telah diturunkan oleh Verlinde perlu ditinjau ulang agar sesuai dengan teori gravitasi kuantum.

Biasanya prinsip holografik dipelajari dalam konteks relativistik tetapi Verlinde telah berhasil menurunkan hukum gravitasi Newton sehingga memberikan ruang penelitian baru terkait kajian gravitasi non-relativistik. Di dalam artikel ini penulis melakukan diskusi terkait dengan kajian gravitasi non-relativistik yaitu fenomena gravitoelektromagnetisme. Topik ini menarik untuk dikaji karena gravitasi pada pendekatan medan lemah memiliki bentuk yang analogi dengan gaya elektromagnetik. 
Dengan menggunakan invariansi Lorentz, gravitasi dapat menghasilkan medan gravitomagnetik yang digenerasi oleh "arus massa". Menurut (Lense dan Thirring dalam Jin, 2014), massa yang berotasi akan menghasilkan medan gravitomagnetik yang bertanggung jawab terhadap presisi orbit planet dan adanya seretan kerangka (frame dragging). Fenomena-fenomena tersebut telah tervalidasi oleh beberapa eksperimen belakangan ini (Ruggiero dan Tartaglia, 2002). Yang membedakan kajian ini dengan kajian gravitoelektromagnetisme konvensional adalah penulis mendiskusikannya berdasarkan konsep gaya entropik berdasarkan koreksi teori gravitasi kuantum.

Pertama penulis akan menyajikan analisis entropi yang sesuai dengan gravitasi kuantum. Dengan menggunakan GUP penulis mengaitkan hubungan antara momentum dengan energi karakteristik yang diemisikan oleh suatu lubang hitam. Setelah mengetahui energi karakteristik yang tersebut maka dapat dihitung perubahan luas horizon sehingga diperoleh ungkapan entropinya. Kondisi lubang hitam penulis terapkan karena pada dasarnya konsep holografik yang dirumuskan oleh Verlinde menggunakan rumusan entropi Bekenstein yang diperoleh di horizon lubang hitam. Selain itu lubang hitam merupakan suatu objek yang mendeskripsikan kaitan antara gravitasi dan struktur ruang-waktu dengan variabel-variabel termodinamika bahkan aspek kuantum dengan sangat jelas (Tiandho dan Triyanta, 2016; Tiandho dan Triyanta, 2014). Kedua, berdasarkan definisi entropi penulis kemudian mencoba menurunkan hukum gravitasi Newton sebagai interpretasi gaya entropik sehingga dapat ditentukan potensial Newton serta densitas massa efektifnya. Selanjutnya, dengan menggunakan aproksimasi medan gravitasi lemah penulis melakukan perumusan efek gravitoelektromagnetisme berdasarkan potensial dan densitas massa yang telah diperoleh. Untuk menyederhanakan proses perhitungan, digunakan satuan natural unit dengan ketentuan $c=\hbar=k_{B}=1$.

\section{KOREKSI ENTROPI MENURUT GRAVITASI KUANTUM}

Dalam bagian ini penulis akan menurunkan definisi entropi sesuai dengan koreksi GUP pada suatu lubang hitam. Melalui rumusan ini akan diperoleh ungkapan entropi sebagai fungsi luasan horizon yang kelak akan dikaitkan dengan prinsip holografik. Dengan sedikit manipulasi aljabar maka ungkapan GUP dalam persamaan (1) dapat dituliskan dalam,

$$
\delta p \geq \frac{\delta x}{2 \alpha l_{p}^{2}}\left(1-\sqrt{1-\frac{4 \alpha l_{p}^{2}}{\delta x^{2}}}\right)
$$

Tanda minus pada persamaan (2) dipilih agar kembali mereduksi pada ketidakpastian klasik untuk kasus koreksi $l_{p}^{2} \rightarrow 0$. Pada kajian medan lemah maka dapat diterapkan kondisi titik tinjau cukup jauh dari sumber gravitasi sehingga nilai $l_{p}^{2}$ relatif kecil dibandingkan satu. Dengan demikian ungkapan ketidakpastian momentum dapat diuraikan berdasarkan deret Taylor sebagai berikut:

$$
\delta p \geq \frac{1}{\delta x}\left[1+\left(\frac{\alpha l_{p}^{2}}{\delta x^{2}}\right)+2\left(\frac{\alpha l_{p}^{2}}{\delta x^{2}}\right)^{2}+O\left(l_{p}\right)^{5}+\ldots\right]
$$

Dalam gravitasi kuantum kaitan antara energi karakteristik partikel yang diemisikan oleh lubang hitam diperoleh dari rumusan energi pada lower bound dan hubungan energi-momentum dispersi untuk partikel berenergi tinggi (Gambini dan Pullin,1999; Camelia, Arzano \& Procaccini, 2004). Karena massa partikel yang diemisikan oleh suatu lubang hitam jauh lebih kecil dibandingkan 
massa lubang hitam itu sendiri maka dipenuhi kondisi, $\varepsilon \approx p$ sehingga energi dari partikel radiasi Hawking adalah,

$$
\varepsilon \geq \frac{1}{\delta x}\left[1+\left(\frac{\alpha l_{p}^{2}}{\delta x^{2}}\right)+2\left(\frac{\alpha l_{p}^{2}}{\delta x^{2}}\right)^{2}+O\left(l_{p}\right)^{5}+\ldots\right]
$$

Berdasarkan koreksi kuantum, ketika suatu lubang hitam mengemisikan partikel atau mengabsorpsi partikel yang berenergi $\varepsilon$ maka perubahan area minimal lubang hitam dapat diungkapkan sebagai (Medved \& Vagenas, 2004),

$$
\Delta A_{\min } \geq 8 \pi l_{p}^{2} \varepsilon \delta x
$$

Dalam perhitungan temperatur Hawking yang diturunkan melalui prinsip ketidakpastian diketahui bahwa $\delta x$ berkaitan dengan event horizon yaitu $\delta x=2 \pi r_{h}$ (Adler, Chen \& Santiago, 2001). Selain itu kita juga dapat menyatakan kaitan area lubang hitam dengan event horizonnya sebagai $A$ $=4 \pi r^{2}$. Dengan melakukan substitusi persamaan (4) pada (5) dan dengan menggunakan definisi area kita akan memperoleh,

$$
\Delta A_{\text {min }} \geq 8 \pi l_{p}^{2}\left[1+\frac{\alpha l_{p}^{2}}{\pi A}+2\left(\frac{\alpha l_{p}^{2}}{\pi A}\right)^{2}+O\left(l_{p}\right)^{5}+\ldots\right]
$$

Pada kajian dasar teori informasi lubang hitam dan teori holografik telah diketahui bahwa entropi lubang hitam merupakan ukuran informasi yang berkaitan dengan interior lubang hitam dan tidak dapat diakses oleh observer di eksterior. Dengan demikian peningkatan minimal entropi secara sederhana bergantung pada "bit" informasi yang dalam artikel ini dinyatakan sebagai unit dasar entropi, $b$. Melalui definisi tersebut, hubungan antara perubahan entropi dan perubahan area lubang hitam dapat diekspresikan sebagai berikut,

$$
\frac{d S}{d A}=\frac{\Delta S_{\min }}{\Delta A_{\min }}=\frac{b}{8 \pi l_{p}^{2}\left(1+\frac{\alpha l_{p}^{2}}{A \pi}+2\left(\frac{\alpha l_{p}^{2}}{A \pi}\right)^{2}+O\left(l_{p}\right)^{5}+\ldots\right)}
$$

Persamaan (7) dapat diuraikan dalam deret Taylor untuk kondisi horizon yang cukup besar dibandingkan panjang Planck. Kemudian dengan mengintegrasikan entropi dalam uraian deret Taylor tersebut akan diperoleh,

$$
S \approx \frac{A b}{8 \pi l_{p}^{2}}-\frac{\alpha b \ln A}{8 \pi^{2}}+\frac{\alpha^{2} b l_{p}^{2}}{8 \pi^{3} A}-\frac{3 \alpha^{3} b l_{p}^{4}}{16 \pi^{4} A^{2}}+\ldots
$$

Dengan menyatakan entropi hasil koreksi kuantum gravitasi sebagai $S=S_{0}+S_{K}$, dimana $S_{0}$ adalah entropi Bekenstein $S_{0}=A / 4 / p^{2}$ maka dapat dipilih $b=2 \pi$ agar ungkapan entropi yang diperoleh akan tereduksi menjadi entropi Bekenstein ketika tidak melibatkan faktor koreksi panjang Planck. Secara eksplisit entropi koreksi GUP dapat dituliskan sebagai,

$$
S=\frac{A}{4 l_{p}^{2}}-\frac{\alpha \ln A}{4 \pi}+\frac{A}{4 l_{p}^{2}}\left[\sum_{i=1} c_{i}\left(\frac{\alpha l_{p}^{2}}{\pi A}\right)^{i+1}\right]
$$

dimana $c_{i}$ adalah suatu konstanta tak berdimensi yang nilainya sesuai dengan suku yang berkaitan. 


\section{GRAVITASI NEWTON SEBAGAI GAYA ENTROPIK}

Jacobson mengajukan kaitan antara entropi dengan geometri ruang-waktu untuk menurunkan persamaan Einstein (Jacobson, 1995). Dalam perumusannya, Jacobson menggunakan hukum ke II termodinamika atau teorema Clausius, $d E=T d S$. Verlinde menggunakan konsep tersebut untuk mengajukan ide bahwa apabila terdapat objek bermassa $M$ maka objek tersebut akan menghasilkan layar holografik sferis yang membawa informasi terkait dengan energi yang tersebar pada suatu jarak tertentu. Misalkan terdapat objek kedua bermassa $m$ yang berada pada posisi $R$ dari benda bermassa $M$ maka benda tersebut akan berasosiasi dengan layar holografik yang memiliki luas area $A=4 \pi R^{2}$. llustrasi uraian ini ditunjukkan oleh Gambar 1, dimana informasi yang dimaksud dinyatakan dalam bilangan bit. Melalui analogi fenomena osmosis pada membran semipermeabel dengan penurunan entropi Bekenstein dapat didefinisikan gaya entropik yang muncul pada partikel akibat membran yang memiliki temperatur $T$ yaitu,

$$
F \delta x=T \delta S
$$

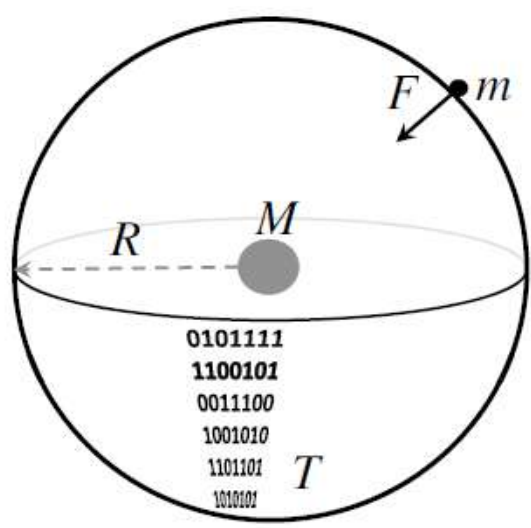

Gambar 1. Sebuah partikel bermassa $m$ di dekat layar holografik yang dihasilkan oleh objek bermassa M (Verlinde, 2011).

Karena seperti dinyatakan bahwa entropi terkait dengan informasi maka dapat dinyatakan suatu bilangan bit sebesar $N$ bersesuaian dengan area layar holografik, $N=A / G$ dimana $G$ adalah suatu konstanta baru yang kelak akan dikenal sebagai konstanta gravitasi Newton. Energi yang tersebar secara merata pada layar holografik dapat ditentukan berdasarkan prinsip ekuivalensi, $E=$ NT/2. Karena informasi energi pada layar holografik dihasilkan oleh benda bermassa M maka dapat dinyatakan bahwa energi tersebut berasosiasi dengan $E=M$. Oleh karena itu untuk layar holografik dengan luasan $A=4 \pi R^{2}$ dapat diperoleh temperaturnya sebagai,

$$
T=\frac{G M}{2 \pi R^{2}}
$$

Berdasarkan persamaan (7) dan persamaan (5) maka dapat dituliskan perubahan entropi akibat adanya proses "absropsi" partikel berenergi $\varepsilon$ sebagai,

$$
\Delta S=\frac{2 \pi \varepsilon \delta x}{1+\frac{\alpha l_{p}^{2}}{A \pi}+2\left(\frac{\alpha l_{p}^{2}}{A \pi}\right)^{2}+O\left(l_{p}\right)^{5}+\ldots}
$$


Karena dalam kasus ini partikel yang akan terkait dengan layar holografik memiliki massa $m$ maka energinya dapat dinyatakan sebagai, $\varepsilon=m$ sehingga dengan menggunakan uraian Taylor ungkapan perubahan entropi dapat dinyatakan sebagai,

$$
\delta S=\frac{2 \pi m \delta x}{1+\frac{\alpha l_{p}^{2}}{A \pi}+2\left(\frac{\alpha l_{p}^{2}}{A \pi}\right)^{2}+O\left(l_{p}\right)^{5}+\ldots}
$$

Dengan menggunakan persamaan (10) akan diperoleh ungkapan besarnya gaya entropik setelah diuraikan dengan deret Taylor sebagai,

$$
F=\frac{G M m}{R^{2}}\left(1-\frac{\alpha l_{p}^{2}}{4 \pi^{2} R^{2}}-\left(\frac{\alpha l_{p}^{2}}{4 \pi^{2} R^{2}}\right)^{2}+O\left(l_{p}\right)^{5}\right)
$$

Dapat dilihat dari persamaan (14) bahwa ketika faktor koreksi panjang Planck tidak dilibatkan maka gaya entropik yang diperoleh mereduksi pada gaya gravitasi Newton yang telah lama dikenal. Hasil gaya entropik yang diperoleh dalam penelitian ini analogi dengan hasil penurunan gaya gravitasi non-relativistik yang diturunkan berdasarkan persamaan Friedmann (Merino dan Obregon, 2017). Adanya faktor koreksi panjang Planck dalam rumusan gaya gravitasi yang diperoleh mengindikasikan persamaan ini mendukung rumusan teori kuantum gravitasi.

Berdasarkan kaitan antara gaya dengan potensial, dengan asumsi bahwa gaya entropik yang diperoleh dalam penurunan ini bersifat sebagai gaya konservatif, maka dihasilkan ungkapan potensialnya sebagai,

$$
\Phi=-\frac{G M}{R}\left(1-\frac{\alpha l_{p}^{2}}{12 \pi^{2} R^{2}}-\frac{\alpha^{2} l_{p}^{4}}{80 \pi^{4} R^{4}}+O\left(l_{p}\right)^{5}\right)
$$

Seperti telah diungkapkan sebelumnya bahwa gaya Newton telah dikenal luas sebagai aproksimasi medan lemah dari teori relativitas Einstein. Dalam kondisi tersebut dapat dirumuskan hukum Gauss gravitasi yang secara matematis ekuivalen dengan hukum gravitasi Newton sebagai, $\nabla^{2} \Phi=4 \pi G \rho$ dimana $\rho$ adalah densitas massa dari objek yang menarik objek lain. Hubungan antara hukum Gauss gravitasi dengan hukum gravitasi Newton ditunjukkan melalui teorema divergensi. Dengan menggunakan persamaan (15) dan menggunakan definisi Laplacian pada koordinat bola dapat diperoleh densitas massa di sekitar objek $M$ atau densitas efektif sebagai,

$$
\rho_{\text {eff }}=\frac{\alpha l_{p}^{2} M}{8 \pi^{3} R^{5}}\left(1+\frac{\alpha l_{p}^{2}}{2 \pi^{5} R^{2}}+O\left(l_{p}\right)^{3}\right)
$$

Hal menarik dari densitas massa yang diperoleh dalam artikel ini adalah densitas massa disekitar objek $M$ tidaklah nol. Berbeda dengan densitas massa yang diperoleh melalui teori gravitasi Newton konvensional, densitas massa yang muncul dalam perhitungan ini kemungkinan dapat dipandang sebagai fluktuasi kuantum yang dihasilkan oleh benda $M$ melalui suatu proses kuantum yang sejauh ini belum diketahui (Merino dan Obregon, 2017). Selain itu melalui hasil perhitungan tersebut dapat disimpulkan bahwa pada limit tanpa koreksi kuantum, $l_{p} \rightarrow 0$, maka densitas massa di sekitar M akan bernilai nol dan ini sesuai dengan tinjauan gravitasi Newton konvensional.

\section{KOREKSI ENTROPI TERHADAP GRAVITOELEKTROMAGNETISME}

Seperti dinyatakan sebelumnya, gravitoelektromagnetisme adalah suatu efek yang telah diprediksi melalui hubungan antara gravitasi dengan struktur ruang-waktu untuk kondisi medan 
lemah. Efek gravitoelektromagnetisme dapat teramati ketika suatu objek bermassa bergerak sehingga dapat menimbulkan atau berinteraksi dengan medan gravitomagnetik. Munculnya medan gravitomagnetik berkaitan dengan fenomena frame-dragging yang telah terverfikasi oleh satelit Gavity Probe B (Ruggiero dan Tartaglia, 2002).

Dengan menggunakan aproksimasi medan lemah maka persamaan Einstein dalam teori relativitas umum dapat diungkapkan dalam suatu persamaan yang analogi dengan persamaan Maxwell. Aproksimasi medan lemah merupakan solusi persamaan Einstein dalam vakum yang memenuhi kondisi medan linear. Dalam keadaan tersebut maka metrik tensor $g_{\mu \nu}$ dapat diungkapkan sebagai penjumlahan metrik Minkowskian $\eta_{\mu v}$ dengan metrik perturbasi $h_{\mu v}$ (Tiandho, 2016),

$$
g_{\mu v}=\eta_{\mu v}+h_{\mu v}
$$

Di dalam artikel ini penulis menggunakan definisi metrik $\eta_{\mu v}=\operatorname{diag}(1,-1,-1,-1)$ dan seluruh komponen suku perturbasi memiliki nilai jauh lebih kecil dari satu, $\left|h_{\mu v}\right|<<1$. Invers dari metrik tensor ini dapat dinyatakan sebagai $g^{\mu \nu}=\eta^{\mu \nu}-h^{\mu \nu}$. Dengan menggunakan definisi,

$$
\bar{h}_{\mu v}=h_{\mu v}-\frac{1}{2} \eta_{\mu v} h
$$

dengan $h=h_{\alpha}^{\alpha}$ pada persamaan Einstein, $G_{\mu v}=8 \pi G T_{\mu v}$ sehingga dapat diperoleh,

$$
\square \bar{h}_{\mu v}=16 \pi G T_{\mu v}
$$

dengan $\square=\frac{1}{c^{2}} \frac{\partial^{2}}{\partial t^{2}}-\nabla^{2}$ Solusi dari persamaan dapat dituliskan sebagai retarded potential,

$$
\bar{h}_{\mu \nu}=-4 G \int \frac{T_{\mu \nu}\left(t-\left|\mathbf{x}-\mathbf{x}^{\prime}\right|, \mathbf{x}^{\prime}\right)}{\left|\mathbf{x}-\mathbf{x}^{\prime}\right|} d^{3} x
$$

dengan $\mathbf{x}$ adalah vektor spasial dan $T_{\mu \nu}=T_{\mu \nu}(t, \mathbf{x})$. Tensor momentum energi $T_{\mu \nu}$ memiliki perilaku yang analogi dengan 4-arus elektromagnetik $J_{\mu}$ dan potensial tensor $h_{\mu v}$ memiliki perilaku analogi dengan potensial medan $A_{\mu}$. Pada kondisi aproksimasi medan lemah dapat digunakan asumsi $\left|T_{00}\right|>>\left|T_{i j}\right|$ dan $\left|T_{0 i}\right|>>\left|T_{i j}\right|$ sehingga dari persamaan (19) komponen potensial tensor memenuhi $\left|\bar{h}_{00}\right|>>\left|\bar{h}_{i j}\right|$ dan $\left|\bar{h}_{0 i}\right|>>\left|\bar{h}_{i j}\right|$. Berdasarkan asumsi-asumsi tersebut dan perilakunya yang analogi dengan medan elektromagentik maka dapat dituliskan,

$$
\bar{h}_{00}=-4 \Phi ; \bar{h}_{0 i}=2 A_{i}
$$

Di sini $\Phi$ adalah potensial skalar yang dirumuskan pada persamaan (15) dan dalam teori gravitoelektromagnetisme potensial ini terkait dengan medan gravitoelektrik sedangkan $A_{i}$ adalah potensial vektor yang terkait dengan medan gravitomagnetik. Pada dasarnya potensial vektor dibentuk oleh momentum angular $L$ dari objek yang berotasi dan koordinat spasial dari pengamat,

$$
\mathbf{A}=\frac{G}{r^{3}} \mathbf{L} \times \mathbf{r}
$$



sebagai,

Berdasarkan kondisi gauge Lorentz hubungan antara potensial $\Phi$ dan $\mathbf{A}$ dapat didefinisikan

$$
\frac{\partial \Phi}{\partial t}+\frac{1}{2} \nabla \cdot \mathbf{A}=0
$$

Faktor koreksi $1 / 2$ pada persamaan muncul karena kondisi gauge Lorentz pada elektromagnetisme berhubungan dengan medan elektromagnetik yang memiliki spin-1 sedangkan pada medan yang ditimbulkan dalam fenomena gravitoelektromagnetisme terkait dengan medan berspin-2.

Dengan analogi gravitoelektrik $\mathbf{E}_{G}$ dengan medan listrik dan gravitomagnetik $\mathbf{B}_{G}$ dengan medan magnet maka dapat didefinisikan,

$$
\begin{aligned}
& \mathbf{E}_{G}=-\nabla \Phi-\frac{1}{2} \frac{\partial \mathbf{A}}{\partial t} \\
& \mathbf{B}_{G}=\frac{1}{2} \nabla \times \mathbf{A}
\end{aligned}
$$

Dengan demikian dapat disusun satu set persamaan Maxwell untuk efek gravitoelektromagnetisme sebagai,

$$
\begin{aligned}
& \nabla . \mathbf{E}_{G}=4 \pi G \rho \\
& \nabla . \mathbf{B}_{G}=0 \\
& \nabla \times \mathbf{E}_{G}=-\frac{1}{2} \frac{\partial \mathbf{B}_{G}}{\partial t} \\
& \nabla \times \frac{1}{2} \mathbf{B}_{G}=\frac{\partial \mathbf{E}}{\partial t}-4 \pi G \mathbf{j}
\end{aligned}
$$

Berdasarkan koreksi entropi pada kuantum gravitasi diperoleh bahwa dalam gaya gravitasi dimungkinkan munculnya densitas tambahan sebagai akibat adanya fluktuasi kuantum atau quantum foam. Dengan demikian, melalui persamaan (25) dapat diketahui bahwa medan gravitoelektrik yang dihasilkan oleh suatu objek bermassa $M$ besarnya adalah,

$$
E_{G}=\frac{G M}{R^{2}}\left(1-\frac{\alpha l_{p}^{2}}{4 \pi^{2} R^{2}}-\left(\frac{\alpha l_{p}^{2}}{4 \pi^{2} R^{2}}\right)^{2}+O\left(l_{p}\right)^{5}\right)
$$

Berdasarkan hubungan persamaan (26) dengan ungkapan densitas massa efektif di sekitar objek seperti pada persamaan (16) maka secara umum massa jenis suatu benda di permukaannya dapat dinyatakan sebagai, $\rho=\rho_{0}+\rho_{\text {eff }}$ dengan $\rho_{0}$ adalah massa jenis benda tanpa koreksi panjang Planck. Dengan demikian medan gravitoelektrik pada persamaan (26) juga dapat dinyatakan sebagai $E_{G}=E_{G 0}+E_{G e f f}$ dengan $E_{G 0}$ adalah medan gravitoelektrik yang telah lama diketahui dalam tinjauan konvensional sedangkan $E_{\text {Geff }}$ adalah medan gravitoelektrik yang ditimbulkan oleh adanya massa jenis efektif akibat fluktuasi kuantum.

Melalui definisi medan gravitomagnetik pada persamaan (24) dan definisi vektor potensial pada persamaan (22) maka dapat ditentukan besarnya medan gravitomagnetik yang dihasilkan oleh suatu objek yang berotasi. Misalkan saja tinjauan dilakukan pada bidang ekuitorial dari suatu objek simetri bola maka secara eksplisit medan gravitomagnetiknya dapat dinyatakan sebagai berikut,

$$
B_{G}=\frac{G}{2} \frac{L}{r^{3}}
$$


Untuk objek simetri bola maka momentum angularnya dapat didefinisikan sebagai, $L=I_{\text {bola }} \omega$ dimana $I_{\text {bola }}$ adalah momen inersial bola yang nilainya $I=2 M r^{2} / 5$ dan $\omega$ adalah frekuensi angular objek. Namun karena adanya fluktuasi kuantum maka densitas massa dari objek bermassa $M$ secara lengkap dinyatakan dengan ungkapan sebagai hasil penjumlahan densitas massa konvensional dengan densitas efektifnya. Dengan demikian, untuk kasus tepat di permukaan ekuitorial maka massa benda beserta dengan faktor koreksi fluktuasi kuantumnya dapat diungkapkan dalam,

$$
M_{\text {tot }}=M\left(1-\frac{\alpha l_{p}^{2}}{4 \pi^{2} R^{2}}-\left(\frac{\alpha l_{p}^{2}}{4 \pi^{2} R^{2}}\right)^{2}+O\left(l_{p}\right)^{5}\right)
$$

sehingga medan gravitomagnetik berdasarkan koreksi entropi secara eksplisit dapat dituliskan sebagai,

$$
B_{G}=\frac{2 \pi G}{5 r T} M\left(1-\frac{\alpha l_{p}^{2}}{4 \pi^{2} R^{2}}-\left(\frac{\alpha l_{p}^{2}}{4 \pi^{2} R^{2}}\right)^{2}+O\left(l_{p}\right)^{5}\right)
$$

Dengan demikian tampak bahwa adanya koreksi akibat fluktuasi kuantum menyebabkan nilai medan gravitomagnetik dan medan gravitoelektrik perlu dikoreksi ulang. Adanya faktor koreksi ini diharapkan dapat meningkatkan presisi dari pengukuran efek gravitoelektromagnetisme. Selain itu tampak juga bahwa untuk tinjauan tanpa melibatkan faktor koreksi panjang Planck atau $l_{p} \rightarrow 0$ maka hasil perhitungan medan gravitoelektrik dan gravitomagnetik yang diperoleh dalam artikel ini akan mereduksi pada tinjauan konvensional.

\section{SIMPULAN}

Dalam artikel ini penulis telah menunjukkan bahwa gravitasi dapat dipandang sebagai sebuah gaya entropik yang dihasilkan akibat perubahan entropi pada layar holografik. Ungkapan gravitasi Newton dapat diturunkan secara langsung melalui teorema Clausius atau hukum kedua termodinamika. Pelibatan faktor koreksi panjang Planck dalam proses penghitungan gaya entropik menuntun penulis untuk melihat adanya fluktuasi kuantum di sekitar objek bermassa M. Hal tersebut mengakibatkan densitas massa objek juga harus dikoreksi ulang. Karena ide konsep gaya entropik dapat mereduksi pada hukum Newton tentang gravitasi maka ini mengindikasikan bahwa ia juga dapat diterapkan untuk mengkaji kasus-kasus medan gravitasi lemah seperti efek gravitoelektromagnetisme. Dengan menggunakan rumusan gaya dan densitas massa yang telah dikoreksi dapat dihitung besarnya medan gravitoelektrik dan medan gravitomagnetik dengan melibatkan faktor koreksi panjang Planck. Adanya faktor koreksi ini diharapkan dapat meningkatkan akurasi dalam proses pengamatan efek gravitoelektromagnetisme selanjutnya.

\section{REFERENSI}

Adler, R. J., Chen, P. \& Santiago, D. I. (2001). The generalized uncertainty principle and black hole remnants. General Relativity and Gravitation, 33(12): 2101-2108.

Amati, D., Ciafaloni, M. \& Veneziano, G. (1989). Can spacetime be probed below the string size?. Physics Letters B, 216: 41-47.

Camelia, G. A., Arzano, M. \& Procaccini, A. (2004). Severe constraints on the loop-quantum-gravity energy-momentum dispersion relation from the black-hole area-entropy law. Physical Review D, 70: 107501. 
Ciufolini, I. et al. (2013). Fundamental physics and general relativity with the LARES and LAGEOS satellites. Nuclear Physics B, 243: 180-193.

Dzierzak, P., Jezierski, J., Malkiewicz, P. \& Piechocki, W. (2010). The minimum length problem of loop quantum cosmology. Acta Physica Polonica B, 41:. 717-726.

Gambini, R. \& Pullin, J. (1999). Nonstandard optics from quantum space-time. Physical Review D, 59: 124021.

Garay, L. J. (1995). Quantum gravity and minimum length. International Journal of Modern Physics A, 10(2): 145-165.

Jacobson, T. (1995). Thermodynamics of space time: the Einstein equation of state. Physical Review Letter, 75: 1260.

Jin, W. (2014). Gravitomagnetism and Lense-Thirring effect of the sun and planets in the solar system. Progress in Astronomy, 32(3): 282-298.

Maldacena, J. (2014). Testing gauge/gravity duality on a quantum black hole. Science, 344(806): 806.

Medved, A. J. \& Vagenas, E. C. (2004). When conceptual worlds collide: the generalized uncertainty principle and the Bekenstein-Hawking entropy. Phyiscal Review D, 70: 124021.

Merino, A. \& Obregon, O. (2017). Modified entropies, their corresponding Newtonian forces, potentials, and temperatures. arXiv: 1701.01239v1.

Papadodimas, K. \& Raju, S. (2014). Black hole interior in the holographic correspondence and the information paradox. Physical Review Letters, 112: 051301.

Paulson, S., Gleiser, M., Freese, K. \& Tegmark, M. (2015). The unification of physics: the quest for a theory of everything. Annals of the New York Academy of Sciences, 1361: 18-35.

Ruggiero, M. \& Tartaglia, A. (2002). Gravitomagnetic effects. Nuovo Cim. B, 117: 743-768.

Tiandho, Y. \& Triyanta. (2014). Transfer panas lubang hitam schwarzschild. Jurnal MIPA, 37(2): 130135.

. (2016). Dirac particles emission from reissner-nordstrom-vaidya black hole. Journal of Physics Conference Series, 739(1): 012146.

Tiandho, Y. (2016). Weber's gravitational force as static weak field approximation. AIP Conference Proceedings, 1708: 070012.

Verlinde, E. (2011). On the origin of gravity and the laws of Newton. Journal of High Energy Physics,4:. 029(1)-26. 